\title{
和平利用原子能的國际合作
}

\section{И. И. 諾維科夫}

根据联合國大会第九屆会議的决議, 8 月 8 日至 20 日在日內瓦國联大厦举行了和平 利用原子能國际科学技術会議。参加这个会議的有 73 个國家的 1,400 个代表, 和大致闹

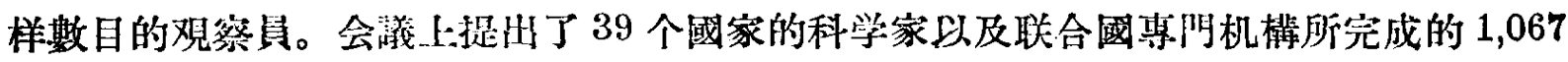
篇科学論文，其中在全体会諓和小組会上宣筫和討論的有 450 篇。

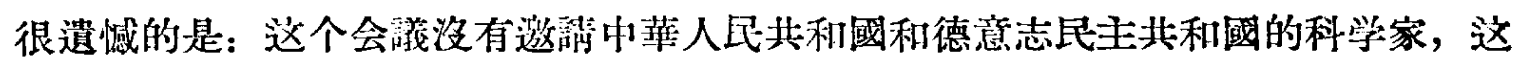
是毫繁道理地对这兩个國家歧視的結果。

会議於 8 月 8 日早晨開幕。瑞士联邦主席彼蒂彼埃对参州会議的代表們和为數众多 的客人們表示㳔迎。

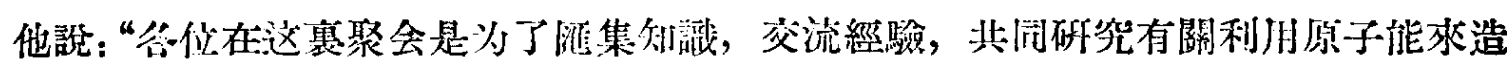

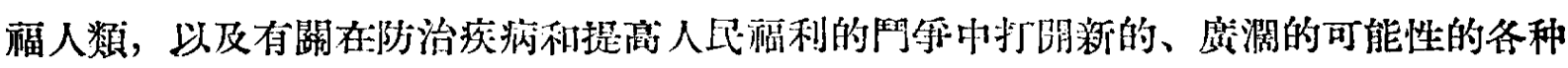
問題。”

彼蒂很埃表示深信：会猛将作出为迲到服务於和平事業的目的而实行合作的榜样。

接着联合國秘書長哈駱含尔德问大会致詞。他指出会淁具有特別重大的意义。他希

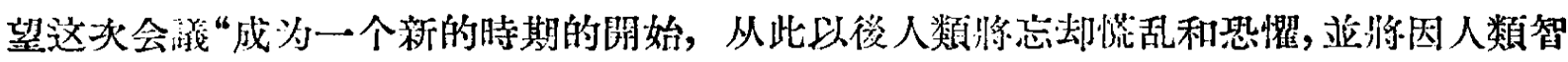

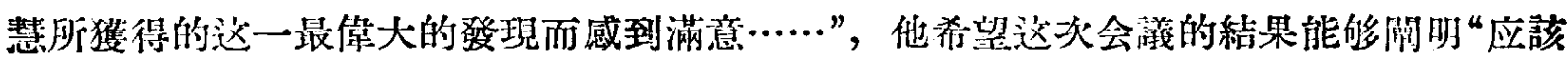
怎样在实踐上运用这一發現，……以提高人類生活水本和稫利”。

苏联、美國、英國、法國和印度政府領袖給这次会㼁折來了贺电。各該國家代表团 的团長在满台上:在与会者的掌声下宜讀了这些賀电。

苏联部長会漼主店布尔加寧的电父中察道:

“苏联非常重視在不是为了战孚和毁娍的目的而是为了倒造的目的, 为了造稆人類,

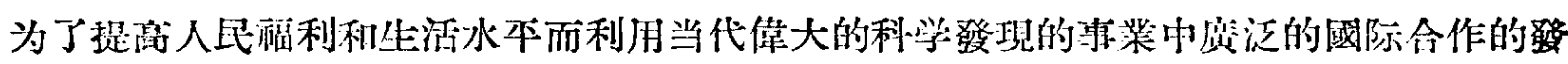

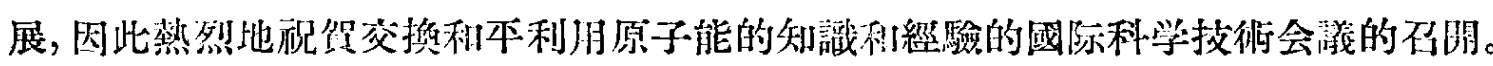

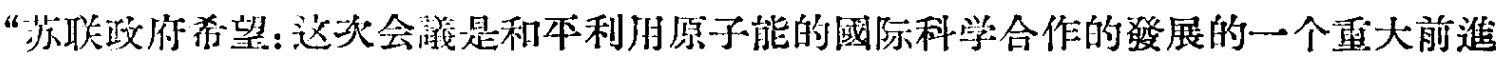
步驟, 证顽会議在实琴这一崇高任务上獲得最大成就。”

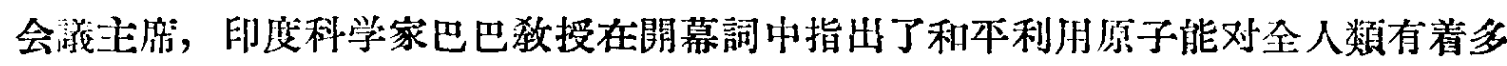
樜重大的意义。

他說：僅在 20 世紀的前 50 年中，地球上的居民就由 15 億人增州到 23 億人。格据 專家的估計, 到公元 2,000 年师增州到 35-50 隐人。

在工業發達的國家中，現在所需的能量已經是每人 20 千瓦小時以上，而且还將不断
1 月号
科学邀報
- 23 
增加。由此可知，能的資源問題已成了一个迫切的問題。

目前，世界上所用的能的 $80 \%$ 是依靠燃燒煤、石油和天然点取得的, $15 \%$ 是依靠燃 暩木料和農業廢品，祇有 $1.5 \%$ 是依靠水力。在当前对能量的要求日益增加的䞨势下， 根据學家們的意見，已經調查过的、䋎济上適於開探的煤、石油和天然气的啫藏可能在 100 年以內就要消耗尽。利用原子核分裂所放出的能量的可能性給解决这个問題指出了 一条道路。使一顿鈾全部分裂, 就可以獲得相当於燃燒 250-300 万顿煤所獲得的全部能

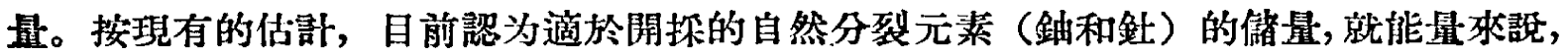
超过煤、石油和天然气的現有資源 16 倍，根据另一种估計，甚至要超过 39 倍。

巴巴强調指出：实际利用分裂过程中所释放出來的原子能的可能性在日前已完全被 証实了。他指出在苏联已經建成的、把电力供給國家电力網已經一年多的、功敦为 5,000 千酉的原子能电力站就是一个明顯的例子。許多國家（苏联、美國、英國、法國）都正 在建古不同類型的、更巨大的原子能电力站。最近烧年內原子能在力能總生㐬师所做的 百分比将取决於基本投資的大小和獲得的电力的成本，而投資的大小和电力成本炎取决 於原子能电力站反应堆的原子工藝、類型和結棈完普到们䐴程度。

接着, 巴巴談到了原子试器的問題, 他指出: 这个題目虻然是会議日程笔图以外的

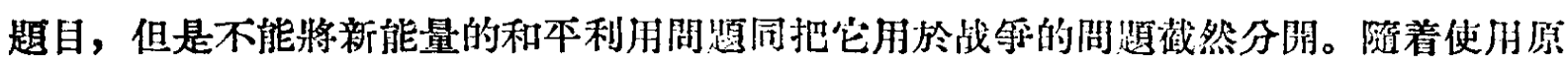
子能的工業在世界上許多地區的出現, 獲得大量可分致物質和慗造原子武器的閒題就成

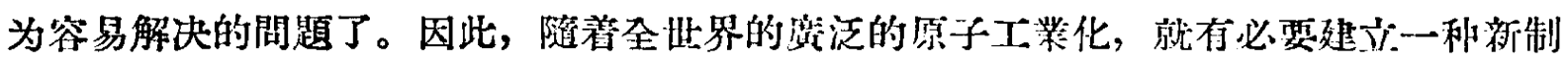
度，在这制度下各个大國洼成維護和平的协㼁。

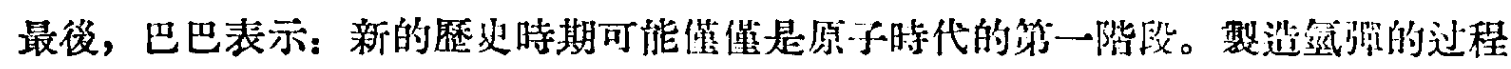
部明：通过对輕元素聚合过程中的熱核子区应的控制以取得能是可能的。将來沃件事成 功了的時候，对全世界來說，能的儲昷問题便最終地永远地㑇决了。

第一次全体会議在確定会議程序和負責人之後結束。

議程包括下列的問題: 全世界对能的需要; 建立告產原子能的企策; 在核子推的 利用方面起作用的因素; 在最近 50 年期間原子能将起的作用; 与原子能有關的保健间 題; 放射性同位素的利用; 和本利用原子能的國际合作; 訓練和培养原子能的夏阿人材; 動力的和实驗的原子反应堆及有關的原子核物理問題; 原子材料的化学、冶金学和工脽 学; 在生物学、農業和医学方面原子能的利用; 在技術和工業方面放射性同位素的利 用。

前 8 个問題在全体会議上討論, 其餘的問題分別在物理及反应堆組, 生物学、医学 和同位素利用組，化学、冶金和工藝組的分組会上討諭。

一共举行了 8 次全体会議和 52 次分組会議。

斯柯貝尔琴院士 (苏联)、拉比（美國）、科克洛夫特（英國）、貝朗（法國）、弗光依 斯（加拿大）被选为会議的副主席。

苏联科学家布洛欣采夫、維諾格拉多夫、康德拉捷夫、庫尔久莫夫、庫尔薩諾夫、庫 普烈維奇、帕拉金、帕謝契尼克、略勃契可夫被推为分組会議的主店和副主席。

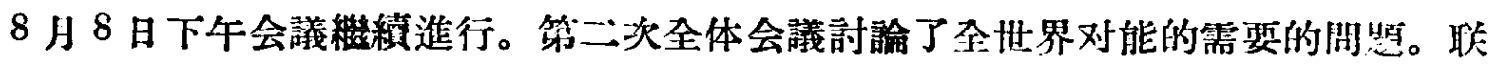
合国所準备的包括 1975-2000 年全世界对能的需要的材料的交件引起了古体代表的 
注意。这个文件指出: 20世紀末，全世界每年对能的需要将此 1952年韽加 7 倍。至 1975 年, 对能的需要將增井近 2 倍, 因此在國际訫劃中就提出了一个能的來源問題。

法國科学家, 法國原子能問題委員会委員艾也栢在自己的嘏告中对这个問題作了弡 掩, 他指出了能的新來源——原子爽源对和本事業的重要性。

他說: 人類应該準备滿足对能的大量需求，大規模利用鈾、銡以及其他人類賴以为 生的巨大能源（如太陽光）的時候很快就要來到了。

艾也烈說: 原子能已進入在工業上成为可能的階段, 它的成本目前虽然暫洔还很不 確定, 但是以後㙷然是要降低的。而且然可争諭地出現了新的利用原子能的可能性, 而 那些从前还沒有能被利用过的簡單的、但又要求大量电力的生方法也將開始在工業上 应用。

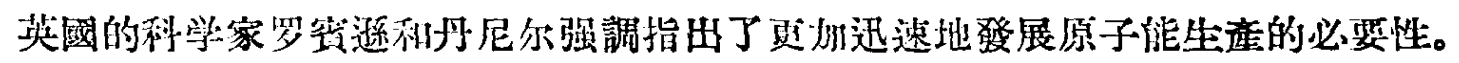

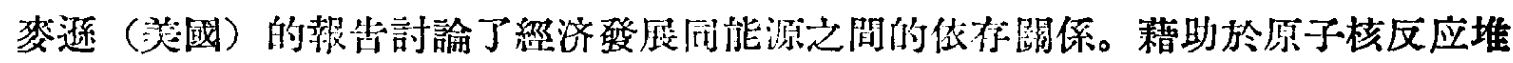

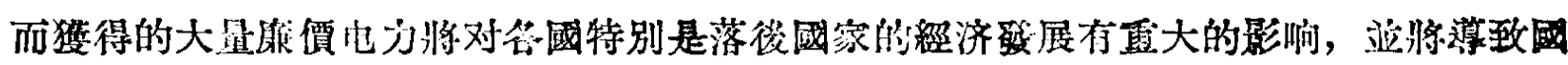
际㚆易的摭大。

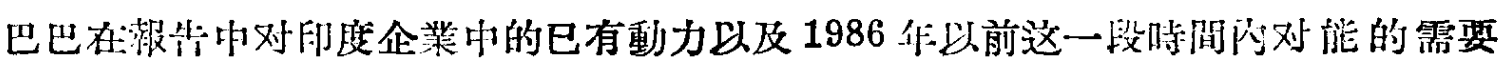
作了估計。比利洔科学家王密尔强調指出: 原子能对他們的國家來說有着首要的意义, 原 子能保証比利時在燃料方面不依賴外國。

唗克激洛伐克科学家謝夫切克的報告討論了原子能的利用对淽足居民个人和社会需 要, 以及对生活条作的改善和文化進步的影响。他指出: 1965-1970 年这些年代重, 在 捷克斯洛伐克動力工業方面原子能的利用将已会有很大的实际意义。

在白天的会議上，南斯拉夫、巴西、澳大利亞、日本、阿梏至、埃及、巴基斯坦、 上色列、鉙蘭等國的代表都發了言。他們一致指出: 全圮界对沱的需要在不久的将來将 只有藉助於原子能和其他将來可能被發現的來源方才能得到满足。晋通的生產動力的方

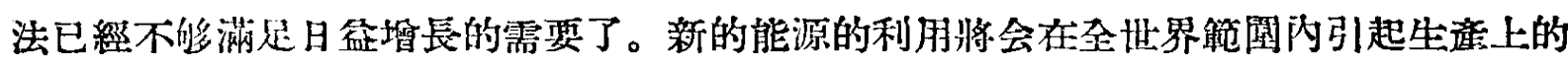
空前發展泣促進新的工業部門的出現。

8月 9 日早上的会議討諭了建立動力原子裝置, 首先是建立原子能电力站的泪邀, 也 討論了在工整上利用原子能以獲取电力的远景。

会竓一開始, 苏联科学家布洛欣采夫和尼科拉也夫作了以“苏联第一个工栄原子能

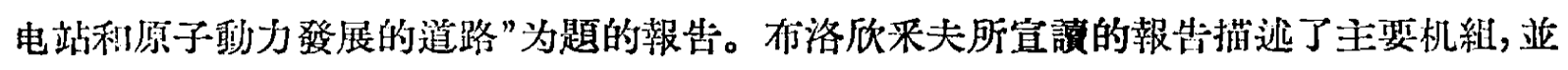
分析了一年來利闸这个电新的經驗, 这个电力站目前还是唯一的在工業的規模上軎为和 本目的而製取和利用原子能的电站。

原子能必站的主要机組, 它的心脿, 是原子区应堆, 放出大量能的鈾核分裂的鏈式 反应就是在反应堆中進行的。苏联原子能电站探用了所謂“熱中子反应堆”，在这种反应

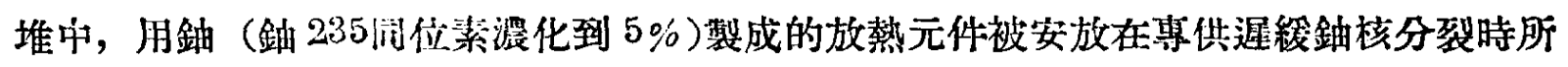
这生的快中子之用的石墨堆中。流經放熱元件的水流吸收鈾核分裂時所放出的熱; 水压 約 100 大气压。加熱到 $260-270^{\circ}$ 的水从反应堆出來後流入熱交換蒸汽發生器, 在这兒 把熱傳給第二回路（所以要用第二回路是由於反应堆中的水具有放射性）的水, 然後冾

1 月号

科学通報

- 25 • 
却到 $190^{\circ}$ 。体靠这个熱量，第二回路中的水形成 12.5 大纸压的、温度 約 $250-260^{\circ}$ 的 蒸汽，这蒸汽淮入㛃動發电能力 5,000 千酉發电机的汽輪机。

布洛欣采夫指出: 在反应堆開動後所測得的反应堆实际指标同計算的指标很好地吻 合.

苏联第一个原子能电站是一个实驗性質的电站。建造它的目的是要明使用这种电 站的可靠性和安全性，並皘累在設計、建造具有更大發电能力的原子能虫力站所必需的

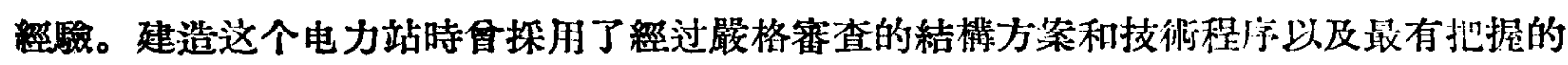

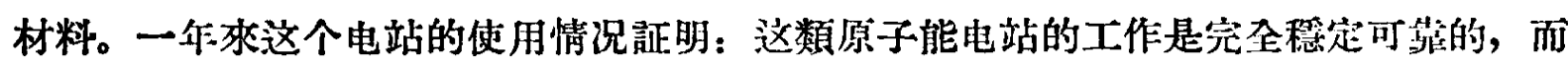
且同远离探煤區的或使用低級燃料的煤發电站羑不多一样經济。这就給这類原子能电站

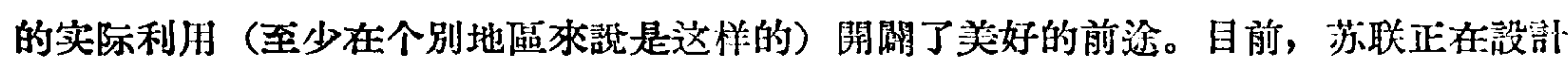
發电能力为 $50,000-100,000$ 千丽的各种不同類型的原子能电站。

布洛欣采夫談到了在原子核燃料化学的物理的成分、減速剂類型（在熱中子反应堆 中）以及取熱方法上各不相同的各种反应堆在原子能电站上应用的远景。

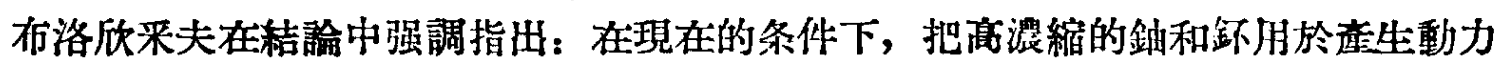
这一事業由於这些材料能在軍事上应用而受到了阻碍。因此, 全人類要求把新的自然㖎 的强大力量祀用於和平目的这一正义合理的願望盆早得到实現, 原子儌力就將盆早走上 席泛發展的道路。

布洛欣采夫的報告引起了熱烈的討論。参加討論的人们他提出了許多關於原子能电 站的技術細節及个別机件的問題和苏耿和平利用原子能的進一步远景的問題。外國科学 家在自己的發言中無論对这个知告本身, 或者对苏联科学的成就都作了很滈的挀價, 全 体会議的主席科克洛夫特为了布洛欣采夫的这个在科学方面和实际方面都很有價值的報 告而向他致謝。

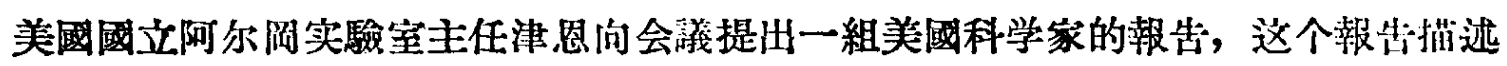

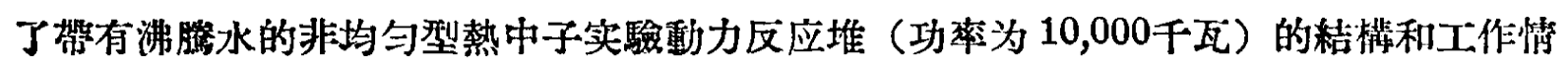
㫛。

在这个反应堆中, 苲汽不是在熱艾换器中形成, 而是直接在反应堆中形成。由於反 应堆內部密度的急剧变化, 会經对这种反应堆的工作的穞定性存在过怀疑, 但是, 䍀尔

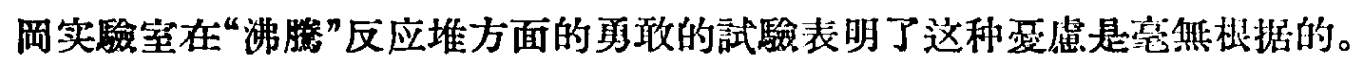

報告中所談到的反应堆有較大的功菜; 根据津恩的意胃, 这种反应堆的功藮还叮以 增加許多倍。討論中指出了“沸膯”应堆的巨大好处, 因为这种反应堆能大大地们化原 子能發电站的設备, 从而降低电站建築和使用的開支, 此外, 还能提语电力站的有效熱 功係數和增加原子核燃料的再生產, 即鈈的道量。会上, 还發表了許多關於建筑和使朋 功率很大的“沙滕”反应堆的困难的意胃。

接着，英國科学家希尔和卓斯林作了關於英國在原子能生疋上的投資的微驻。他們 報道了關於撥給哈威尔原子能研究所試驗站進行科学研究工作的資金的材料。也討論了 英國開始实行發展原子能生產計劃所必需的投資的問題。

美國原子能委員会委員台維斯在報告中歌到了为建設原子能电站所必要的投資的問 題。
- 26 •
科学通 報
1956 年 
8 月 9 日白天的全体会議討論了原子動力的經济問題和針的地位, 並且还討論了有 開使用原子能的法律問題和管理問題。

列恩（美國）和朱克斯（英國）就原子能电力站的經济問題作了報告。

列恩的報跕論述了由規模巨大的原子核發电站取得動力的預計成本。報告人分析了 供应原子能电站的核燃料的成本和經常閉支。他發表了这样一个意見: 原子能發电站發 电的成本“过 15一-20 年後完全可以同煤發电站、石油發电站或水力發电站的發电成本相 比。”列恩宜称：原子能电站將同大部分 1975 年前所建立的一切新發电站梳采。朱克折 的溊告估訐了英國準备建立的第一批原子能电站的电力的可能成本。

英國科学家但諾尔特分析了在原子核動力方面应用釷的方法，指出了使用针的一些 优點。根据但諾尔特的意胃, 过 40 年之後, 大不列顛所需的全部動力将由 15 顿原子核 燃料來保炋。

他說：針是未來的燃料。他認为針比鈾更可贵：釷比鈾僻量多 5 倍，價格只有鈾的

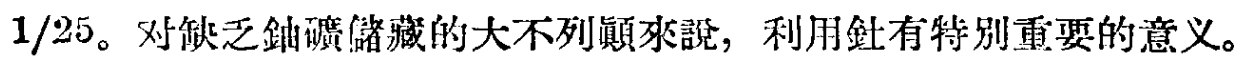

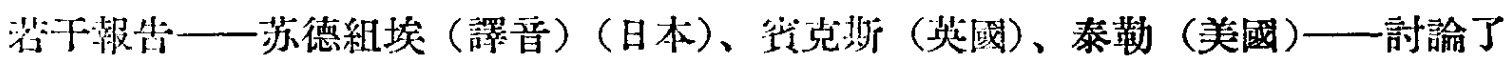
由於工作中放射㨫物質的放射線伤害的危險而引起的法律和管理問題。

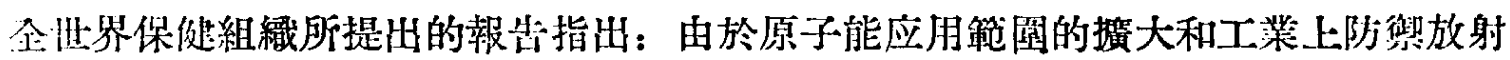
線的必要性，在保健机關面前擺着一些重大的任务。建議在保健計劃中栲虑到像逊当地

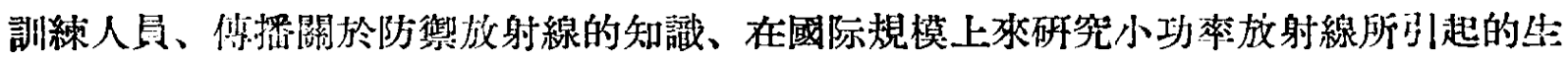
物效应，以及在放射線的影响下所迹生的遺傳效应等等措施的重要性。

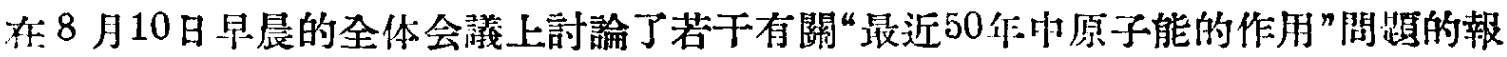

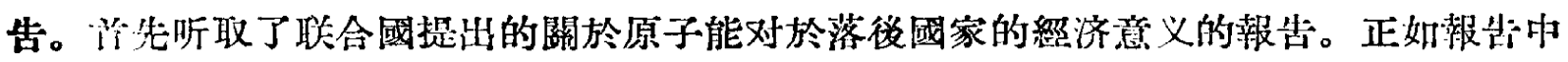
指出的，原子能的应用使这些國家能够更平衡地癹展自己的工業, 使他們有可能獾得更

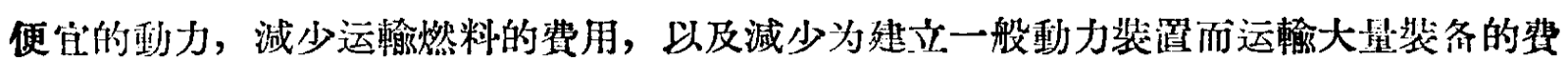
阴。

朋拿大的学者 J. 台維斯在報告中開明了原子能对於加拿大的意义。他指出加拿大没 然有丰富的水力資源，有煤利石油的大量譈藏，足以保証較低的电力成本，但是原子能在 加拿大仍将有很大的作月。國內的鈾的儲藏量足够完成發展原子動力的“最度泛的訐劃”。 实現了这媩劃以後原子能将成为加拿大的电力的一种主要的（如果不是唯一的）源泉。

埝卭尔作了關於在法國發展电力生这的報告。由於原子电力站在經济方面將愈來愈 有利，他提计要預見到它們的最廣泛的应用。其次他談到原子电力站的“寿命”的間題， 因为動力生產的成本是同它的寿命有關的。

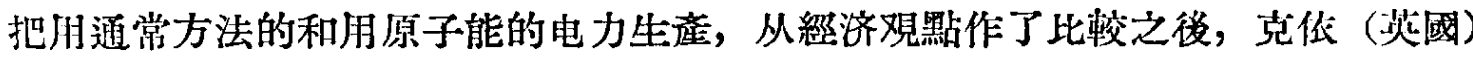
得出了結論, 他謨最近50年內原子能对於其他一切動力源泉桃說将会成为最有力的对于。

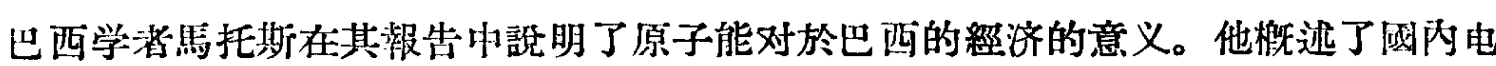
力的情况，韭發表了有關巴西在未來的电力方面需要的一系列意見。

哈威尔原子能研究所所長科克洛夫特叙述了在英國發展原子動力的政府的計劃。根 据他的話, $1 \frac{1}{2}-2$ 年後英國將有一个功䇣 5 万千酉以上的原子能电站投入生座。这个电站
1 月号
科学通報

- 27 • 
有兩个石墨減速的、气体冷却的原子反应堆。为了保証安全使用, 每个反应堆都包在密

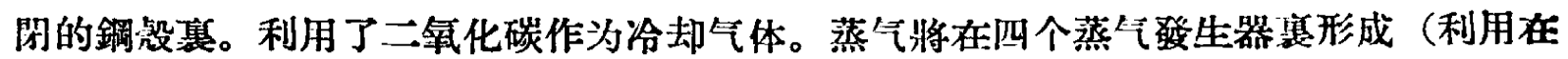
反应堆中变熱的二氧化碳的熱), 蒸气从發生器進入四个汽輸發电机豪。

1960－1965 年英國还打算再建立 12 个原子能电力站。約在 1970 年時，英國的 新 建电力站中原子电力站將佔优势，而到 1975 年所需的电力約有一牛将由原子电力站 出。

在阿根廷代表伊拉奧拉戈伊齐的報告中證明了原子能对於國內电力的意义。他在垠 占的結尾時号召加强國际合作，利用原子能造福人類。

麥耶尔 (美國) 談到了同建設及使用原子能电力站有關的經济研究工:作。

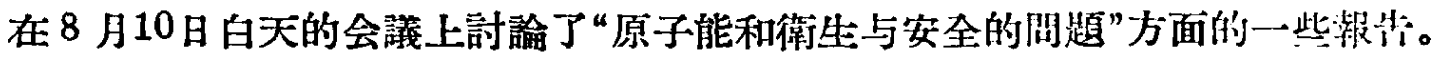

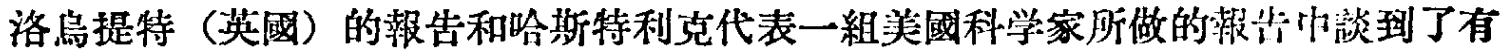
關保護从事原子能研究和在原子工業部門中工作的人們健尿的問題。茄联医生古西科卡

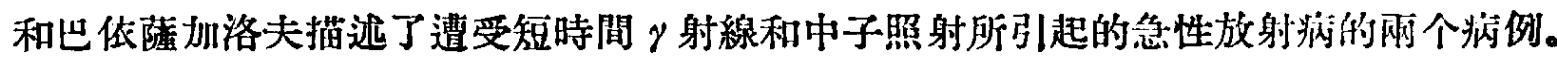
由於探取了有效措施, 患病媵第三个月病人的工作能力完全恢復了。在一年牛的覌祭过 程中証朋这种恢復是很稳定的。報告中詳細地叙述了医療过程、所使用的手段和方法。 研究人得出了結論, 他䜊早期（預防的）使用抗生素和各种止血剂在治㜣急性放射病時 是有效的办法。

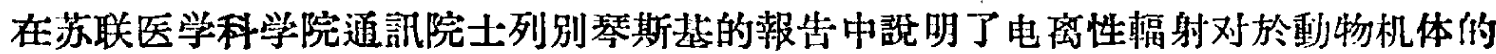

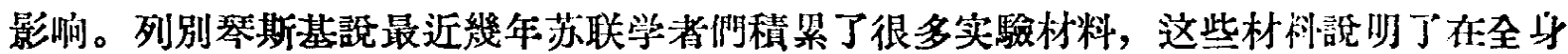

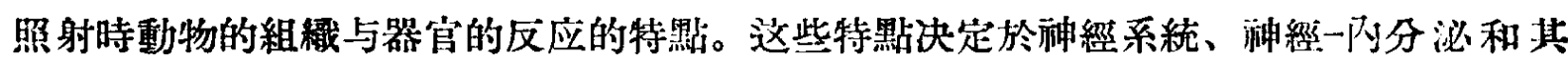
他一些机構的参与。电离性輻射对於組織和器官的㨁接作用所迹生的局部的和初期的变 化，是闰神䅔的及体液的作用的生理效应相結合的。

報告人提出了在电离性輻射作用於動物的实驗裏有關中橾种經系繶机能狀况变化的 原因的若于假設，指出輻射首先有可能对腦子直接發生作用，根据他的意見，外面的衝

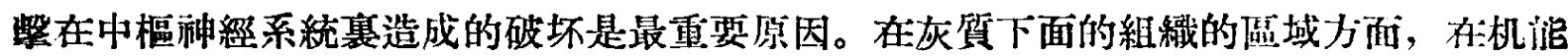
狀况中發生重要变化。为了踣实自己的結論，列別琴斯基举出了丰富的实驗材料。

白天的全体会謡臨結束時，听取了哿庫洛夫和底特里赫代表美國学者所作的關於深 障从事反应堆工作的人們安全的措施的都告。英國学者提出的關於这个題目的频步是由 玨尔宣墳的。

美國学者認为保障在放原于堆的建築中工作的人的紹对安全日前还是作不到的（戟 們不能闰意这种意見)。在報告中訜，“原子核反应堆的活動被称为是安全的，任求实上 这安全是靠不住的”。“如果在設計和运轉中沒有錯誤的話，原子核反应堆的功後将不政

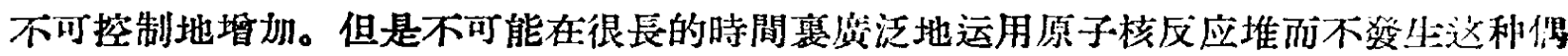
然的錯誤。”反应堆功率不断增加而發生的事故，从開始到結束还不到一秒鐘，因论需娒 有很快動作的自動控制和有效的安全装置。

在 8 月 11 日早晨的会議上結束了这些問題的討論。接着就討論了放射性问位素 在 工業各部門、農業部門、科学研究工作中和医学中应用的問題。艾別索德 (美國) 和湑 利格明（英國）做了有關这一題目的報告。艾別索德举出很多利朋放射性同位絭的储 
子, 特別是目的在於研究化学和物理过程、座品和藥品的椧汾素、病人的治療、探伤、 以及研究生理和生物化学过程等等的例子。艾別索德說在美國工業中由於应用放射性同 位素, 節省了一万万美元以上。澤利格明在報告中举出很多工業和掕術各部門利用放射 性同位素的例子, 特別是測量管子應蝕, 確定管路中漏水和漏气的地方, 辨認和啛別地 下深处的頁岩和煤層等。

苏联科学院通訊院士薩馬林参加討諭了这些報告。他說苏联工業中也廣泛地应用了 同位素。以下的事实就証明了这點, 在苏联科学文献中有 200 种以上關於用放射性同位 素解决的各种技乪問題的論著。特別在冶金过程的研究中獲得了有價值的結果。薩馬林 强調指出，國际間交流应用同位素的經驗將促進各國工業的進步。

庫尔薩諾夫院士的報告 “在苏联利用放射性同位素於生物和農業中” 引起全体会墥 参加者注意。苏联学者椚在示踪原子的帮助下全面研究了植物吸收肥料的过程, 研究了 根系的机能, 並且查朋了根能从土壤中吸收二氧化碳, 確定了植物中各种过程進行的速 度, 特别是营养物淮入和移動的速度。在研究光合作用時得出了重要的結果。磪定了光 的强度和光諨成分对於在植物葉中形成的初級產品的成分有很大影响。这就閒䦥了影响 植物的發展及其特性的实际可能性。苏联应用示踪原子進行的生物学和農学研究对於鋠 業有很大实际意义。他們在植物营养过程的理解方面得到了很多新的結果, 提出了更完 善的施肥方法, 改進了農作物概外施肥的方法等等。

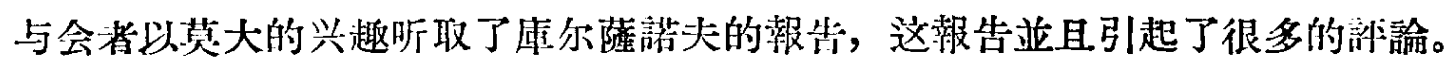

联合國的粮食及農業組織提泏的有關应用同位素於農業的報告中指出, 应用原子能 將促進各國生活水本的提滈。

報告中說：大家知道，为了保証 50 年以後可能增加雨傍的居民的粮食，作作至少

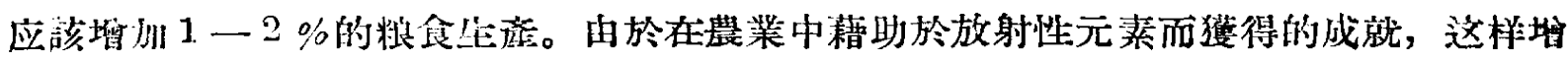
加精食生產是有可能的。

会㼁絬束時听取了格留放夫（英國）和窩尔門（美國）的關於排除放射性廢物問題 的款告。

8 月 $11-19$ 日会議繼續分組淮行。

参加整个会議的苏联学者們提出了 102 个科学報告, 其中在会議上宣謮和討論过的 有 70 个。美國的学者在会議上宣讀了 176 个郝告, 而英國学者做了 65 个報告。

在会議期間举办的和本利用原子能的科学技術展覽会是非常有兴趣的。它㙷示了各 國一一苏联、美國、英國、法國、加拿大、比利時、丹货、瑞典和挪威一一的成就。

在苏联领內，丰富的喓磺标本、苏联原子能發电站和实驗反应堆的模型、各式各样 的儀器、以及㗱明苏联在和本利用原子能方面的成就的圖片和交献, 引起了極度泛的注 意。

美國在展覽舘中也佔了很大範圍。在靠近國联大廈的尃門建築的大樓中展出了功來 100 千瓦的物理原子反应堆。

最傑出的学者一一玻尔、劳价斯、韋克斯勤、貝特、列普而斯一命格、德格委希、 利比、菏蘭德、庫尔薩諾夫、科克洛夫特一一在晚上作了各利題目的報告。
1 月号
科学通 報 


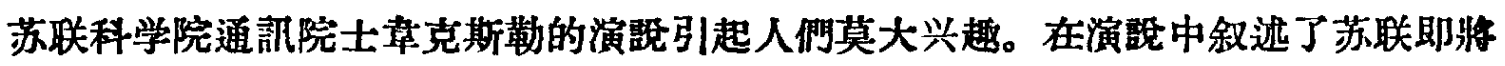
完成的世界上最大的 100 镱电子伏能量質子廻旋加速器的建造。

劳命斯叙述了美國在基本粒子加速器方面進行研究的情况。目前在加速器中獲得强 大粒子流的問湎引起美國物理学家極大的注意。

苏联代表們参覌了日內瓦歐洲研究中心的各个实驗室, 那裹建築有所謂“强聚焦”的 250 億电子伏能量的質子呬旋加速器, 还参覌了英國最大的哈威尔原子能研究所。

会議上關於和本利用原子能的各个方面和各种問題的討諭是在各國兴者的合作及相 互諒解的气氛中僬行的。

和平利用原子能工作的巨大規模以及此工作对於人類未來的意义，促使的个细家对 这工作關心，並使介紹其他國家在这方面的成就成为極有㿽和極有價值的事情。相互交

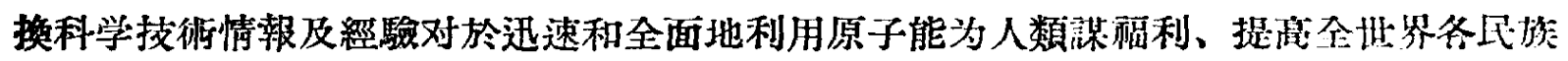
的物涭积利和生活水本有着巨大的意义。

由於在会相互交換了意見，原子能在動力、工業和技値、農業、生物学和医学 方面应用的远景就更明顯了。我們現在可以更明確地想像出原子能的未本及其在最短時 期內将給人類帶來的福利，只要科学家和工程師們的精力都只用於原子能的和平利用方 面而不是用來改進大規模展殺和破坏的武器。

在工業.上建立原子能發电站獾得电能，这是發展原子動力的道路之一。原子能澄电 站將用新的、更强大的功椊來補充已有的能源, 並且对那些水力資源很少或者不能很快 利用，同時煤、石油、煤气的開探又不能滿足能的需要的國家或地區将有头等的意义。 概据会議上所公佈的資料，我們有理由可期待在最近五年內在世界各个地區最少将造成 10 个本均功來 20 万千瓦的原子能發电站。这些目前都将只是試驗性的發电站, 而且它 們的建設沸用比燒煤的电站要貴些。但是很清楚，在此基礎上将建成更完善和这經济的 類型的电站。因此在最近十年內，原子能發电站獲得电能的成本看來將只此普逝电站秒 微高一些, 然而到以後的十年是可能低於普通电站的。

顯然，在选擇原子能發电站的類型洔,各个國家都要从自己的具体的經济条作洲發。 因此原子動力的發展在各个不同的國家将取不同的方式。例如在英國最常使用的型式是 气体冷却反应堆，因而在最初時期建設的原子能發电站主要将使用这称型式的反应堆。 如果考慮到英國的水力資源不大，而根据各种情况來看，提愄煤的開探量灭不可能，那 麼就不能不期望英國在原子能發电站的建設方面大力加緊進行工作。科克洛夫特所說的 原子動力的關始發展“对於我們正好是時候”这句話是很能訜朋問題的。

在美國有着大量的各种各样的維济的和地理的區域，因此各种類型的原子批發心站 都能得到推廣（“沸膯”類型反应堆，水一水反应堆，液体金屬冾却反应堆，快速中一个反应 堆等), 对於各种類型的原子能發电站, 現在正隻行着相当咶泛的研究。闹時, 由於有 大量容易開探的煤礦，所以 1975 年以前美國原子能發电站的發电量在總發电的中所们 比例將不会超过 $1-15 \%$ ，而在英國此時將会佔 $50 \%$ 了。

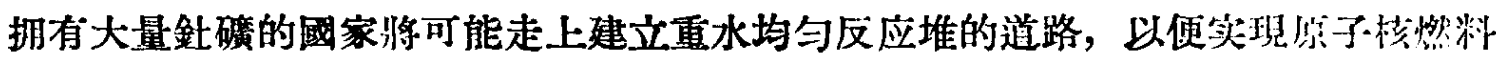
（鈾一233）的拱大再生道。 
日前的实际問題就是要改善原子榜燃料在原子反应堆內的利用, 即要提嵪从每單位 重量所得到的能量。正如在会墔上所公佈的，通过原子核燃料數次偱环的方法，（即 把 反应堆內的燃料使缃好幾次, 每次循环後就進行再提煌）可以在熱中子反应堆內把从單 位重量脸中得到的能量提离到 5-10 倍。改善核子燃料利用的第二种方法是在“快中子” 反应堆內進行核子燃料的㨨大再生逢。在这些反应堆內淮行分裂的不僅是鈾 235 , 而且也 有鈾238。同時，每汾耗 1 公厅的鈾 235，可以得到超过 1 公斤的鈈 239。根据会上公倠 的材料，在这些反应堆荛原子核燃料再生部本可能是 1.5-1.9。製造这些有利的反应堆 目前还有很多的工蓺技術上:的困难。

旧於上:述的問題，在物理学和反应堆分組会上作的報告引起了很大的兴趣。

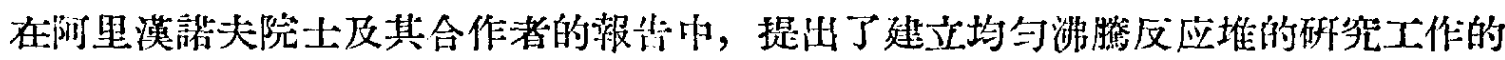
結果，在此反应堆中原子榜燃料处於溶解或者睬浮於液体中的狀态。美图的研究人員在

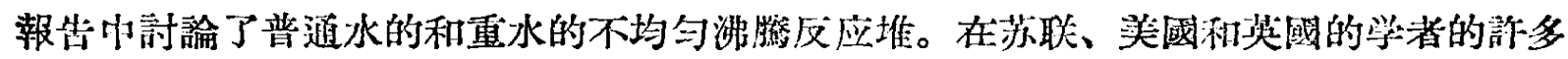
報告中，分析了關於建立液体金屬冷却熱中子反应堆的答种問題，指虫领是最合遥的一 和金犀。会議上都很注意苏联和美國学者所詳細研究的石哭減速水冷却的非均匀反应堆, 以及極有發展前途的水一水反应堆。美國、资國和法國的学者報道了他們的關於建古“快 中子”区应堆的工作。

苏联学者提出了大量的叙述实驗性反应堆及在其中所進行的工作以及原子核物理学

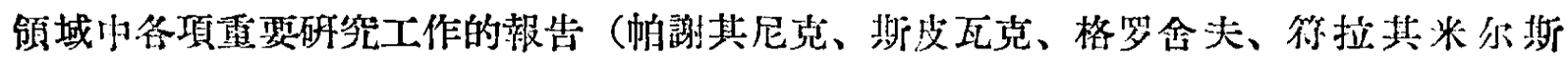

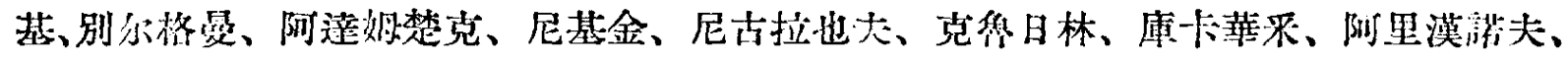
布尔戈夫、安东諾夫、克拉新、加拉寧、费恩別尔格、弗蘭克、谷列維奇、波米的邱克 及其他学者)。

狂改進原子能技術方面，化学过程和冶金过程起着很大的作用。反应堆需要特殊的 材料，其中包括極高純度的金易。另一方面，大量的强烈放射性物質（特別是工作川放

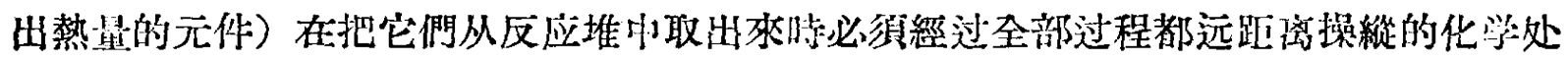
理。化学組、治金組和工藝組的会济討諭了这些重要的問題，在会上苏联学者作了很成 功的發言（也蘭諾夫、沙烏柯夫、帕拉夫久克、格尔里特、什魏传夫、沃罗比也夫、雅

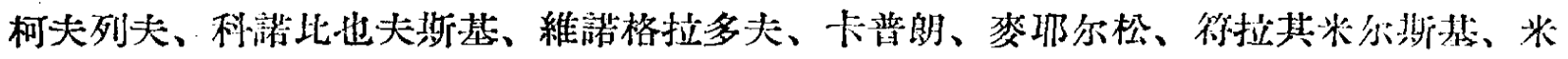
赫也夫及其他的学者的報告)。

苏联学渚的關於放射線对金屬及其他材料的性質的影响，以及關於控制鈾的生新的 方法的款告引起了很大的兴趣。在这个分組的許多次会議上还討論了地質方面的阔面， 特別是有關分析世界上鈾及針的儲藏量及有關勘探这些磺床的方法的問題。

原子動力的發展引起了大量放射性分裂座物的生道和積累, 由此就座生了如何保藏

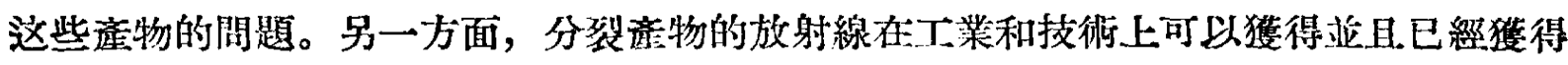
了应用。侧如由这些產物中可以得出放射性的鉋, 它是在 $\gamma$ 探伤器、放射療法上所探川 的珍贵放射源泉，还可以得出其他的放射性元素。分裂这物可用於殺菌藥剂、医学哭械

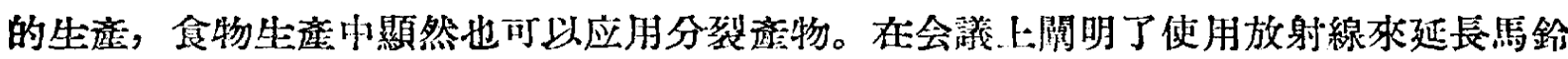
薯和㠇㭉的保存期限以及防治对農栄有害的昆虫和奇生虫的远景。例如，在美國就有成 效地進行了大規模隇蛁的实媛，办法是散播大量 $\gamma$ 射線照射㷋失詓生殖能力的雄蚆。照

1 月号

科学通報 
射猪肉可防旋毛虫。放射線同時还可以用於人工道生笑变, 用中子照射植物种子, 或用 射線長時間照射田中的植物，可以得到新的有價值的農作物品种。

放射線对於化学反应的促進作用对工業特別有利, 它在化学及化学工業中開闒了完 全新的可能性。在各种工壆控制的儀器中运用放射線是特別有效的。

大家也都知道应用放射性同位素作为示踪原子对於化学、生物学、冶金学及其他过 程的研究有着怎样的意义。

苏联学者在会議上報道了他們在上迅各方面所獲得的許多重要結果(康得拉拉夫, 巴 赫、費尔得曼、麥謝尔、西薩强、克列其科夫斯基、索科洛夫、克得罗夫一集赫受、尼 其帕罗維奇、戈得湜夫、什雷克、帕拉丁、符拉其米諾夫、庫津、奧列霍維其、雅柯夫 列夫、阿里馬林、庫尔久莫夫、約当、薩馬林、格罗津及其他学者的缿告)。

苏联研究人員的關於合金中的擴散和原子間相互作用的研究工作，以及放射化学的 研究及其他的工作引起了会議很大的兴趣。

保証原子設备中的工作人員及周園居民的安全是一項重要的任务。目前已踭緗研究

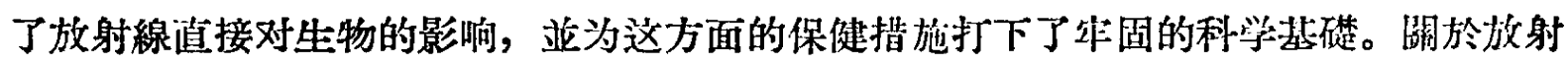
線的間接影响及其所引起的長期的遗傳上的效应則研究得較少（苏眹学者科茲罗婎、法 捷也娃、彼加列夫、列塔維特的報告討論了上迅的一些問題)。

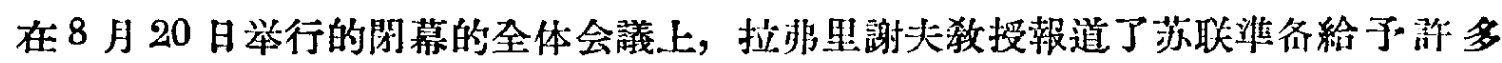
國家以科学技術及生产上的帮助，帮助这些國家为了發展原子核物理学及原子能利本利 用方酒的研究而建立科学实驗壆地。

拉非里謝夫說: “苏联把这帮助看做是这样一种掯施，目的是使每个獾得帮助的國 家将來能够独立地不低賴任何其他國家地在原子能和本利咸方面發展自己的研究与探 索。”

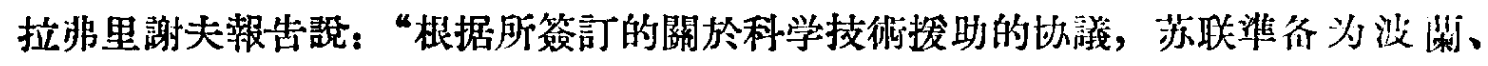
揵克、罗馬尼亞、侧牙利、保加利亞和德意志民主共和國設計立且慗造具有 2,000 下酉 熱功率的实驗原子反应堆和可以獲得能量 2,500 万电子伏的粒子的䢙旅州速器。此项設 計工作已經開始。

反应堆的構造使研究人員能够進行各种材料的工程-物理試驗立具研究各利强设的 放射線对它們的影响。将要用潩縮鈾做燃料, 用普通的水做減速剂和侮熱剂。

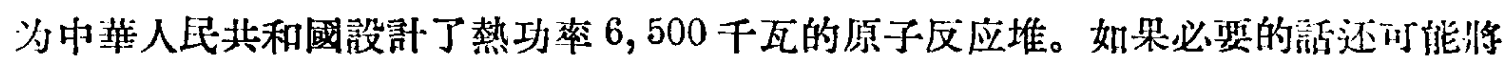

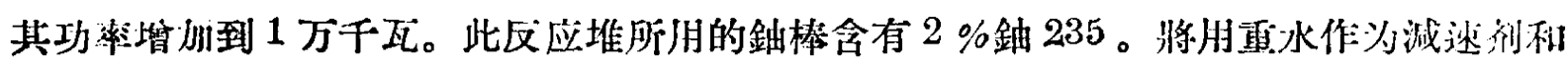

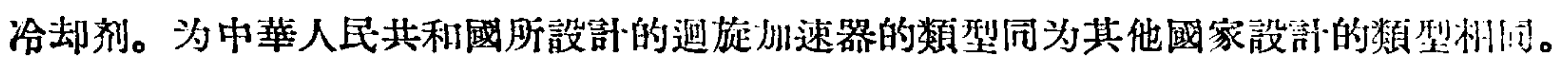

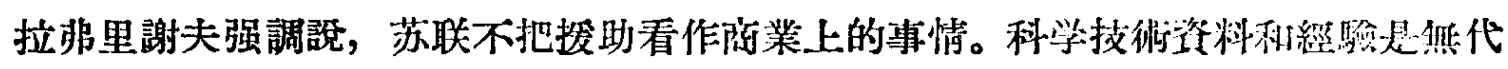
價地提供出來的。獾得帮助的國家支付的实际上僅僅是所供給的設备的慗造贸。

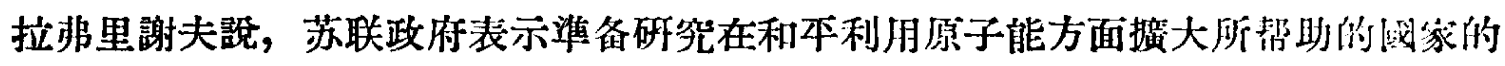

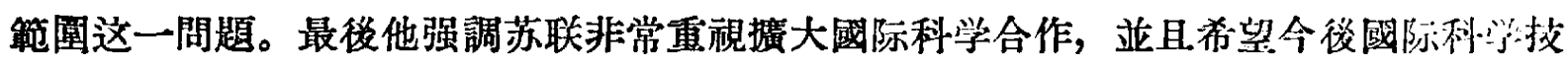
街会議能經常定期石開。

美國代表李比在關於原子能國际合作的報告中也表示了類似的顆望。他强調指计会 
㼁在相当大程度上促進了各國人民在目前及未來和平利朋原子能方面的相互了解。

在英國、墨西哥、挪威、巴基斯坦、波菊、南斯拉夫和其他國家代表的發言中她有 同样的意見。發言者对会議的成就表示滿意, 並强調指出了它对進一步發展國际合作和 杽固各國之間的信任的作用。

南斯拉夫代表薩維奇宣讀了鉄托總統給会議的一扫信，信中特別指出会議在國际意 义方面已超出了純科学会議的範堛, 並且标誌着發展國际合作的新階段。

联合國教育、科学及文化組織主席奧熱在培济和平利用原子能方面的科学幹部的報 步中影到全力推度和普及原子核物理学的新發現及原子能和本利用力面的科学知㵶的問 題。

在会上收到了苏联部長会議主席布尔加寧、美國總統艾森豪威尔、保加利亞人民共 和國部長会議主㢈契尔文科夫的賀信。

巴巴在結束發言時宣䜠了布尔加寧的信，信中指出了会議的成就，並且建議以後經 常定期召闒類似的会議，这封信引起了全体出㢈者熹烈鼓掌。

巴巴在自己的發言中对已討論过的問題做了簡短的總結。在結束自己發言時, 他譙: “在会議結束後, 我們就要回到自己的与進一步和本利用原子能有關的工作中去。而且我 們今天将懷着滿意的心情回到自己的工作中去, 因为我們促進了会議的成功, 证且深信 我們的劳動将以改善地界各地全体人民的生活为目的。”

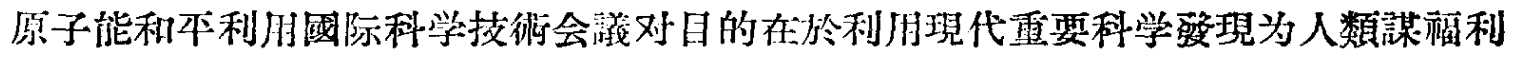

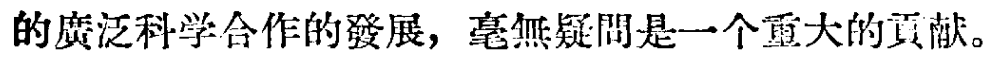

会議指出了苏联的学者和工程师在原子能和不利肪方面有着巨大的卓越的成就。他 們的研究工作件高度科学水本，他們一其努力於在原子能和本利用事業上建立和加强同 各國学者的合作，他們準备同別國科学家分章自己遈方面的經驗与知識，所有这些，侹 得苏联代表团在日內瓦会議上獲得了很大的成就和威信。同時必須指出，在原子能和平 利用的某些重要方面, 苏联学者所進行的工作範圍, 特別是实驗性工作的籁图还不修 席, 应根本加强。

日內瓦会䛨是在原子能和平利用这样重要的領域裏建立國际合作的一个重大步聚; 它标誌着世界学者在發展科学技術合作中的新階段。

在会上交換了經驗和珍貴的科学技術情報, 这將有助於加强和加速各國原子能和本 利用的工作。最近蕉备出版的会議資料将在这方面起很大的作用。

\section{〔沈友玲 金 草 李 恒 譯自“苏联科学院通報” 1955 年 9 月号〕}

